\title{
Timing of Percutaneous Cholecystostomy
}

\author{
Mehmet Akif Üstüner ${ }^{1}$ and Abdulkadir Deniz ${ }^{2}$ \\ ${ }^{1}$ Deparmant of Gastroenterological Surgery, University of Health Sciences, Bursa Highly Specialised Training and Research Hospital, \\ Bursa, Turkey \\ ${ }^{2}$ Deparmant of Gastroenterolgical Surgery, University of Health Sciences, Gulhane Training and Research Hospital, Ankara, Turkey
}

\begin{abstract}
Objective: To investigate the effect of the timing of Percutaneous Cholecystostomy (PC) on morbidity and mortality.

Study Design: Comparative cross-sectional study.

Place and Duration of Study: Deparmant of Gastroenterological Surgery, University of Health Sciences, Gulhane Training and Research Hospital, Ankara, Turkey from 2017 to 2020.

Methodology: The study included 61 patients with ASA 3-4 score, who were underwent PC during the study period. The patients were separated into two groups as Group $1(n=23)$; who underwent PC in the first 24 hours; and Group $2(n=38)$, who underwent PC at 24-96 hours. Morbidity and mortality rates were compared between the groups.

Results: Morbidity was observed in $2(8.7 \%)$ patients in Group 1 and $6(15.8 \%)$ in Group $2(p=0.698)$ with 30-day mortality in $3(13.04 \%)$ patients in Group 1 and $8(21.1 \%)$ in Group $2(p=0.730)$. In the cholangiographic studies, more choledochus stones were determined in Group $2(p=0.041)$. Length of stay in hospital was calculated as mean $10.35 \pm 9.50$ days in Group 1 and $20.03 \pm 45.28$ days in Group $2(p=0.003)$.

Conclusion: No statistically significant difference was found in the morbidity and mortality rates when PC was performed later. The length of stay in hospital was found to be shorter in patients applied with early PC.
\end{abstract}

Key Words: Percutaneous cholecystostomy, Acute cholecystitis, Cholecystectomy, Morbidity, Mortality, Calculous cholecystitis, Acalculous cholecystitis.

How to cite this article: Üstüner MA, Deniz A. Timing of Percutaneous Cholecystostomy. J Coll Physicians Surg Pak 2022; 32(01):20-24.

\section{INTRODUCTION}

Acute cholecystitis (AC) is a commonly seen disease that can lead to empyema, gangrene, perforation, bile leakage, peritonitis, sepsis, and even death. The gold standard in treatment is surgery. ${ }^{1}$ Laparoscopic cholecystectomy is a surgical method incurrent widespread use. ${ }^{2}$

Percutaneous cholecystectomy (PC) in patients with $\mathrm{AC}$ is indicated for elderly patients with multiple comorbidities (ASA >3), in intensive care patients with acalculous cholecystitis, and patients at high risk for surgery with calculous cholecystitis.

The procedure is associated with high morbidity (20-30\%) and mortality rates $(6-30 \%)$ in high-risk patients. $\mathrm{PC}$ is a technique first described in the 1970's by Elyaderany et al., in the context of jaundice secondary to bile duct obstruction and cholelithiasis. ${ }^{3-5} \mathrm{PC}$ has been used around the world for nearly 50 years.

Correspondence to: Dr. Mehmet Akif Üstüner, Deparmant of Gastroenteroloical Surgery, University of Health

Sciences, Bursa Highly Specialised Training and Research

Hospital, Bursa, Turkey

E-mail:dr_ustuner@hotmail.com

Received: September 25, 2021; Revised: October 29, 2021;

Accepted: November 29, 2021

DOI: https://doi.org/10.29271/jcpsp.2022.01.20
However, there is no consensus in literature about the timing of $P C$. The timing of $P C$ ranging from 6 hours to 77 days in various studies, due to contrasting local management practices. Several authors have suggested that early PC reduces length of hospital stay and halt progression of the inflammatory process. ${ }^{5}$

The question is, should the PC be performed at the time of first admission to the patient, or after 24-hour supportive treatment (conservative management by antibiotic therapy and supportive care)? Will there be a difference between the outcome of two methods? According to the hypothesis, late PC will increase sepsis, mortality, and morbidity; butthis needs validation.

The aim of this study was to compare morbidity and mortality in patients undergoing early (first 24 hours, Group 1) or late (24-96 hours, Group 2) PC.

\section{METHODOLOGY}

The study was carried out in the General Surgery Department, Health Sciences University, Gülhane Training and Research Hospital, Ankara, Turkey. The study included 61 patients with ASA 3-4 score, who underwent PC between January 2017 and December 2020. Before PC, ultrasound was performed by radiology for all patients. Computed tomography was applied to required patients. Percutaneous cholecystostomy was performed by interventional radiology using Seldinger method in all patients with 8-F pigtail catheter. 
Patient records were analysed retrospectively electronically.

The diagnosis of AC was made based on physical examination findings, laboratory test values, and imaging methods. Patients with Grade 3, according to the Tokyo 2018 guidelines, ${ }^{6}$ were referred to the Infectious Diseases Department, where antibiotic treatment was administered together with fluid replacement and analgesia, then PC was carried out subsequently. The patients were separated into two groups as Group 1 ( $n=23$ ) applied with PC in the first 24 hours after the onset of symptoms; and Group 2 ( $n=38$ ) that underwent PC at 24-96 hours. The groups were compared in respect of age, gender, body mass index (BMI) values, morbidity and mortality rates, comorbidities, ultrasonography (USG), abdominal computed tomography (CT), magnetic resonance cholangiopancreatography (MRCP), endoscopic retrograde cholangiopancreatography (ERCP) results, length of stay in hospital, operation type, pathological results, and culture results.

Inclusion criteria were: age ranging from 18-99 years with diagnosis of acute cholecystitis, with ASA 3-4 score, who underwent PCatthe study place.

Exclusion criteria were: patients aged $<18$ years, pregnant patients, underwent $\mathrm{PC}$ in the others hospital.

Data obtained in the study were analysed statistically using SPSS for Windows version 23.0 software (SPSS Inc., Chicago, IL, USA). Conformity of the data to normal distribution was assessed with the Shapiro-Wilk test. The Student's t-test was applied for the comparisons of groups, showing normal distribution; and the Mann-Whitney U-test to groups of data that did not show normal distribution. The relationships between groups of categorical data were examined with Pearson test or the Chisquare test. As descriptivestatistics, Median and IQR (Interquartile range) values were presented for numerical variables, while number and $\%$ values were given for categorical variables. A value of $p<0.05$ was accepted as statistically significant. Ethical approval for the study was granted by the Scientific Research Ethics Committee of the University.

\section{RESULTS}

Evaluation was made of a total of 61 patients, who underwent PC, comprising 34 (55.7\%) males and 27 (44.3\%) females with a median age (IQR) of 67 years and median BMI (IQR) of 25.7. Group 1 included 23 (37.7\%) patients, and Group 2, 38 (62.3\%) patients. The median (IQR) length of hospital stay was 10 days (median, 16.3 days). Morbidity was observed in 8 (13.1\%) patients and mortality in 11 (18\%). The comorbidities observed were diabetes at the highest rate $(n=34,55.7 \%)$ and acute Ml at the lowest rate $(n=3,4.9 \%$, Table $)$.

Morbidity was observed in 2 (8.7\%) patients in Group 1 and in 6 (15.8\%) patients in Group $2(p=0.698)$. Thirty day mortality was determined in $3(13.04 \%)$ patients in Group 1, and in 8 $(21.1 \%)$ in Group $2(p=0.511)$. In the cholangiographs done, more choledochus stones were determined in Group 2 ( $p=$
0.041). The length of hospital stay was calculated as median (IQR) 7 days in Group 1 and as median (IQR) 12 days in Group 2 $(p=0.003)$. No statistically significant difference was determined between the groups in respect of age, BMI, number of elective operations, operation types, ERCP results, and comorbidities (Tablell).

Table I: Distribution of general characteristics.
\begin{tabular}{|l|l|l|}
\hline & $n$ & $\%$ \\
\hline Group I & 23 & 37.70 \\
\hline Group II & 38 & 62.30 \\
\hline Male & 34 & 55.70 \\
\hline Female & 27 & 44.30 \\
\hline Age M (IQR) & $67(24)$ \\
\hline BMI M (IQR) & $25.7(3.8)$ \\
\hline Length of hospital stay (hours) M (IQR) & $10(8)$ \\
\hline Morbidity & 8 & 13.10 \\
\hline Mortality & 11 & 18.00 \\
\hline Comorbidities & \multicolumn{3}{|l|}{} \\
\hline Diabetes mellitus & 34 & 55.70 \\
\hline Hypertension & 43 & 70.50 \\
\hline Chronic renal failure & 5 & 8.20 \\
\hline Acute renal failure & 6 & 9.80 \\
\hline Chronic obstructive pulmonary disease & 8 & 13.10 \\
\hline Coronary artery disease & 22 & 36.10 \\
\hline Acute myocardial infarction & 3 & 4.90 \\
\hline SD: Standard deviation; M: Median. & \multicolumn{3}{|l|}{} \\
\hline
\end{tabular}

In the patients, who underwent surgery in both groups, E.coli predomiance was observed most in the cultures of the materials sent for examination, and chronic cholecystitis was observed most in the pathology examination results. Acute cholecystitis was determined most on USG and CT.

When morbidity and mortality were examined in the groups, in Group 1 a liver abscess was observed after the procedure in one patient, and re-drainage was applied because of hematoma in one patient. In the Group 2 patients, liver abscess was observed in one, and re-drainage was applied because of bile leakage in three patients, hematoma in one and abscess in one. Mortality developed because of cardiac arrest in one patient and sepsis in two patients in Group 1. In Group 2, four patients died because of sepsis, two respiratory failure, one pneumonia, and one because of COVID-19 pneumonia.

\section{DISCUSSION}

In this study, patients, who underwent PC in the first 24 hours (Group 1, early) were compared with patients with PC at 24-72 hours (Group 2, late) in respect of morbidity and mortality. Although the morbidity $(p=0.698)$ and mortality $(p=0.730)$ rates were higher in the late $\mathrm{PC}$ group compared to the early group, the difference was not statistically significant. In addition, early PC significantly reduced the length of stay in hospital $(p=0.003)$.

The current gold standard in the treatment of acute cholecystitis is cholecystectomy. However, there is a $5 \%-30 \%$ risk of mortality in early cholecystectomy in elderly critical ill patients at high risk. ${ }^{7}$ 
Table II: Comparison of the demographic and clinical characteristics of the cases in both groups.

\begin{tabular}{|c|c|c|c|c|c|}
\hline & \multicolumn{2}{|c|}{ Group I } & \multicolumn{2}{|c|}{ Group II } & \multirow{2}{*}{$\mathbf{p}$} \\
\hline & $\mathrm{n}$ & $\%$ & $\mathbf{n}$ & $\%$ & \\
\hline \multicolumn{6}{|l|}{ Gender } \\
\hline Male & 14 & 60.9 & 20 & 52.6 & \multirow{2}{*}{0.530} \\
\hline Female & 9 & 39.1 & 18 & 47.4 & \\
\hline Morbidity & 2 & 8.7 & 6 & 15.8 & 0.698 \\
\hline Mortality & 3 & 13.04 & 8 & 21.1 & 0.511 \\
\hline Age M (IQR) & \multicolumn{2}{|c|}{$71(26)$} & \multicolumn{2}{|c|}{$66.5(26)$} & 0.457 \\
\hline BMI M (IQR) & \multicolumn{2}{|c|}{$25.2(3.4)$} & \multicolumn{2}{|c|}{$26.5(5.9)$} & 0.483 \\
\hline Length of hospital stay (hours) M (IQR) & \multicolumn{2}{|c|}{$7(4)$} & \multicolumn{2}{|c|}{$12(6)$} & 0.003 \\
\hline Elective operation & 9 & 39.1 & 9 & 23.7 & 0.200 \\
\hline \multicolumn{6}{|l|}{ Operation type } \\
\hline LC & 6 & 26.08 & 4 & 10.5 & \multirow{3}{*}{0.067} \\
\hline Open & 3 & 13.04 & 1 & 2.6 & \\
\hline Conversion to open & 0 & 0.0 & 4 & 10.5 & \\
\hline \multicolumn{6}{|l|}{ Cholangiograph } \\
\hline Choledocus stone & 1 & 4.3 & 10 & 26.3 & \multirow{3}{*}{0.041} \\
\hline Normal & 1 & 4.3 & 4 & 10.5 & \\
\hline Not applied & 21 & 91.3 & 24 & 63.2 & \\
\hline \multicolumn{6}{|l|}{ ERCP } \\
\hline Papillotomy & 1 & 4.3 & 10 & 26.3 & \multirow{3}{*}{0.089} \\
\hline Stent & 1 & 4.3 & 2 & 5.3 & \\
\hline Not applied & 21 & 91.3 & 26 & 68.4 & \\
\hline \multicolumn{6}{|l|}{ Comorbidities } \\
\hline Diabetes mellitus & 14 & 60.9 & 20 & 52.6 & 0.530 \\
\hline Hypertension & 18 & 78 & 25 & 65.8 & 0.301 \\
\hline Chronic renal failure & 2 & 8.7 & 3 & 7.9 & 0.912 \\
\hline Acute renal failure & 2 & 8.7 & 4 & 10.5 & 0.816 \\
\hline Chronic obstructive pulmonary disease & 1 & 4.3 & 7 & 18.4 & 0.115 \\
\hline Coronary artery disease & 9 & 39.1 & 13 & 34.2 & 0.698 \\
\hline Acute myocardial infarction & 0 & 0 & 3 & 7.9 & 0.167 \\
\hline
\end{tabular}

Therefore, PC can be used in high-risk patients as bridging treatment or as an alternative to surgery. ${ }^{8}$

The Tokyo Guidelines for the Management of Acute Cholecystitis (2018) classify AC in three grades as mild (Grade I), moderate (Grade II) or severe (Grade III). For patients with mild cholecystitis (Grade I), direct surgery is recommended as the treatment approach for low-risk patients (ASA 1-2), and for high-risk patients (ASA 3-4), first antibiotics and supportive treatment, then surgery. In cases with moderate cholecystitis (Grade II), antibiotic and supportive treatments are applied first; and if not successful, drainage is performed first then elective surgery subsequently. If the first step is successful, emergency surgery is performed in low-risk patients and elective surgery is recommended for high-risk patients. In cases with severe cholecystitis (Grade III), antibiotic and supportive treatments is first carried out. If there is no severe organ failure and/or negative predictive factors, emergency surgery is performed in experienced centres if the patient condition is good, but if performance is poor and the patient is not in an experienced centre, percutaneous drainage is carried out. ${ }^{6}$ Consistent with these guidelines, PC was performed in the Grade III AC patients in the current study.

The early PC has many advantages. Early PC prevents the formation of adhesions, severe fibrosis and the destruction of anatomical tissue planes. During gallbladder surgery, these changes can make the surgery very dangerous. PC should be performed as soon as possible., ${ }^{5,9,10}$ There are only a few studies about timing of PC placement. Chok et al. suggested that PC should be perform after three to four intravenous antibiotic doses. ${ }^{11}$

In a randomised, controlled study by Hatzidakis et al. AC patients, who underwent PC medical treatment, were compared with those undergoing to without PC. As $87 \%$ of the high-risk $\mathrm{AC}$ patients showed a response to medical treatment in the first 3 days, it was recommended that the timing of PC should be kept at 72 hours or later. ${ }^{12}$

Chou et al. compared patients with PC done in the first 24 hours with those after 24 hours. The early performance of PC was shown to shorten the length of hospital stay and reduce procedure-related bleeding without increasing mortality. ${ }^{13}$ In the current study, early PC also shortened the length of stay in hospital, but no difference was determined between the groups in respect of bleeding related to the procedure.

Bickel et al. demonstrated that the early (first two days) performance of PC decreased the rates of conversion to open surgery, reporting that the open surgery rate of early PC was $8.3 \%$, while it was $33.3 \%$ in PC done after three days. ${ }^{14}$

In a study by Zazour et al., patients who underwent PC were separated into two groups as early (first 24 hours) and late (after 24 hours) and compared. No significant difference was 
determined in respect of morbidity, and the mortality rates were not compared, but the rate of conversion to open surgery during cholecystectomy was found to be greater in patients late $\mathrm{PC} .^{15}$ In the current study, no significant difference was determined between the groups in respect of morbidity and mortality, but the length of stay in hospital was observed to be longer in the patients applied with late PC.

In several studies, 30-day mortality after PC has been reported to be in the range of $0 \%-25 \% .{ }^{13,16}$ In the current study, the 30 day mortality rate was found to be $18 \%$ with no statistically significant difference between the groups.

In the randomised, multicentre, controlled Chocolate study, PC and LC were compared in high-risk patients. The morbidity rate of major complications of PC was found to be $65 \% .^{17}$

The most frequently obserded PC related complications were drain dislodgment (range 7.2-29.6\%), minor bleeding (range 2.4-7.2\%), minor bile leak (range 1.1-10.4\%) and tube blockage (range $0.6-7 \%)^{5,13,18-21}$

In the current study, morbidity was observed in eight (13.1\%) patients, bile fistula in three $(4.91 \%)$, liver abscess in two $(3.27 \%)$, hematoma in two $(3.27 \%)$, and abscess in the gall bladder in one (1.6\%), for which re-drainage was applied. No significant difference was determined between the groups.

The main study limitations remain the retrospective nature of the study and the limied number of patients, limiting the generalisation of these result.

\section{CONCLUSION}

There was no significant effect on morbidity or on 30-day mortality of early ( $<24$ hours) or late (24-96 hours) performance of PC after starting medical treatment in patients with Grade III acute cholecystitis. However, PC applied early was seen to shorten the length of hospital stay.

\section{ETHICAL APPROVAL:}

Ethical approval for this study was granted by the Ethics Committee of University of Health Sciences, Gülhane Scientific Research Hospital (Decision No. 2020-457).

\section{PATIENTS' CONSENT:}

Written informed consents were obtained from all the patients.

\section{CONFLICT OF INTEREST:}

The authors declared no conflict of interest.

\section{AUTHORS' CONTRIBUTION:}

MAU: Conception, design, supervision, resource, materials, analysis, interpretation, data collection, advanced material processing (AMP), literature search and writing.

AD: Resource, materials, data collection and advanced material processing (AMP).

\section{REFERENCES}

1. Gündoğdu H,Demiral G. Percutaneous cholecystostomy in high-risk geriatric patients with acute cholecystitis. J Coll Phys Surg Pak 2021; 31(07):770-4. doi: 10.29271/jcpsp. 2021.07.770.

2. Jung YK, Choi D, Lee KG. Learning laparoscopic cholecystectomy: A surgical resident's insight on safety and training during the initial 151 cases. Indian J Surg 2020; 83:224-9.

3. Stanek A, Dohan A, Barkun J, Barkun A, Reinhold C, Valenti $D$, et al. Percutaneous cholecystostomy: A simple bridge to surgery or an alternative option for the management of acute cholecystitis? Am J Surg 2018; 216(3):595-603. doi: 10.1016/j.amjsurg.2018.01.027.

4. Macchini D, Degrate L, Oldani M, Leni D, Padalino P, Romano F. Timing of percutaneous cholecystostomy tube removal: A systematic review. Minerva Chir 2016; 71(6): 415-26.

5. Elsharif M, Forouzanfar A, Oaikhinan K, Khetan N. Percutaneous cholecystostomy why, when, what next? A systematic review of past decade. Ann $R$ Coll Surg Engl 2018; 100(8):1-14. doi: 10.1308/rcsann.2018.0150.

6. Okamoto K, Suzuki K, Takada T, Steven M, Strasberg SM, Asbun HJ, et al. Tokyo guidelines 2018: Flowchart for the management of acute cholecystitis. J Hepatobiliary Pancreat Sci 2018; 25(1):55-72. doi: 10.1002/jhbp.516.

7. Patterson EJ, McLoughlin RF, Mathieson JR, Cooperberg PL, MacFarlane JK. An alternative approach to acute cholecystitis. Percutaneous cholecystostomy and interval laparoscopic cholecystectomy. Surg Endosc 1996; 10(12): 1185-8. doi: $10.1007 /$ s004649900275.

8. JungW, Park DE. Timing of cholecystectomy after percutaneous cholecystostomy for acute cholecystitis. Korean J Gastroenterol 2015; 66(4):209-14. doi: 10.4166/ kjg.2015. 66.4.209.

9. El-Gendi A, El-Shafei M, Emara D. Emergency versus delayed cholecystectomy after percutaneous transhepatic gallbladder drainage in grade II acute cholecystitis patients. J Gastrointest Surg 2017; 21(2):284-93. doi: 10.1007/ s11605-016-3304-y.

10. Zehetner J, Degnera E, Olasky J, Mason RA, Drangsholt S, Moazzez A, et al. Percutaneous cholecystostomy versus laparoscopic cholecystectomy in patients with acute cholecystitis and failed conservative management: A matched-pair analysis. Surg Laparosc Endosc Percutan Tech 2014; 24(6):523-7. doi: 10.1097/SLE.0b013e318290 15d2.

11. Chok KS, Chu FS, Cheung TT, T Lam VT, Yuen WK, Chan SC, et al. Results of percutaneous transhepatic cholecys-tostomy for high surgical risk patients with acute cholecystitis. ANZJ Surg 2010; 80(4):280-3. doi: 10. 1111/j.14452197.2009.05105.x.

12. Hatzidakis AA, Prassopoulos P, Petinarakis I. Acute-cholecystitis in high-risk patients: Percutaneous cholecystostomy vs. conservative treatment. Eur Radiol 2002; 12(7):1778-84.

13. Chou CK, Lee KC, Chan CC, Perng CL, Chen CK, Fang WL, et al. Early percutaneous cholecystostomy in severe acutecholecystitis reduces the complication rate and duration of Hospitalstay. Medicine 2015; 94(27): e1096. doi: 10.1097/ 


\section{MD.0000000000001096.}

14. Bickel A, Hoffman RS, Loberant N, Weiss M, Eitan A. Timing of percutaneouscholecystostomy affects conversion rate of delayedl aparoscopic cholecystectomy for severe acutecholecystitis. Surgical End Scopy 2016; 30(3): 1028-33. doi: 10.1007/s00464-015-4290-y.

15. Zarour S, Imam A, Kouniavsky G, Lin G, ZbarA, Mavor E. Percutaneouscholecystostomy in themanagement of high-risk patients present in with acute cholecystitis: Timing and outcome at a single institution. Am J Surg 2017; 214; 456-61.

16. Winbladh A, Gullstrand P, Svanvik J, Sandström P. Systematic review of cholecystostomy as a treatment option in acute cholecystitis. HPB 2009; 11(3):183-93. doi: 10 . 1111/j.1477-2574.2009.00052.x.

17. Loozen CS, Santvoort HC, van Duijvendijk P, Besselink MG, Gouma DJ, Nieuwenhuijzen GA. Laparoscopic cholecys-tectomy versus percutaneous catheter drainage for acute cholecystitis in high risk patients (CHOCOLATE): Multicentre randomised clinical trial. BMJ 2018; 363:3965. doi: 10.1136/bmj.k3965.

18. Lin WC, Chang CW, Chu CH. Percutaneous cholecystostomy for acute cholecystitis in high-risk elderly patients. Kaohsiung J Med Sci 2016; 32(10):518-25. doi: 10.1016/j. kjms.2016.08.006.

19. Pang KW, Tan $\mathrm{CH}$, Loh S. Outcomes of percutaneous cholecystostomy for acute cholecystitis. World J Surg 2016; 40:2735-44.

20. Horn T, Christensen SD, Kirkegard J, Larsen LP, Knudsen AR, Mortensen FV. Percutaneous cholecystostomy is an effective treatment option for acute calculous cholecystitis: A 10year experience. HPB (Oxford) 2015; 17(4):326-31. doi: 10.1111/hpb.12360.

21. Hsieh YC, Chen CK, Su CW, Chan CC, Huo TI, Liu CJ, et al. Outcome after percutaneous cholecystostomy for acute cholecystitis: A single-centre experience. J Gastrointest Surg 2012; 16(10):1860-8. doi: 10.1007/s11605-012- 1965-8. 